\title{
HET SCHOOLONDERWIJS VOOR BEJAARDEN IN DE GEVANGENIS.
}

(Ontleenl ats de bontostoffen now een geschrift orer: "Het schoolondervij in den kerker. Nedevind en Belgie.")

Het is roor de groote huishouding van den Stant reeds een axioma geworden, dat het onderwijs - goed onderwijs - het misdrijf, en zeker ook de armoede verdrijft. Waar het onderwijs in den volsten zin des woords het beste is, dar heeft ook de regter het minst te vonnissen. Deze gelukkige uitkomst wordt door statistieke cijfers gestaafil in het belangrijke verslag - liet eerste van dien aard in Nederland - aan Ien Minister van Justitie uitgebragt, en dienende tot inleiding bij de "Statistiek van het gevangeniswezen orer 1854," door den Inspecteur van 's Rijks gevangenissen, Mr. P. W. Alstorphius Greveinnk.

Werkt het onderwijs in de vrije mantschappij zeer gunstig ter bestrijding van het misdrijf, dan zal het dit ook tegen vernieuwing van misdrijf, in die maatschappij „achter slot en grendel," die maatschappij, door zoo weinigen gekend, door zoo velen scheef beoordeeld.

$\mathrm{Ja}$, het is waarheid! wanneer goed onderwijs in de rije matschappij de strafgevallen vermindert, het onderwijs in de gevangenissen vermindert de recidivisten. Eene gezette waarneming, in eene onzer groote gevangenissen over een tijdvak van zestien jaren (1838-1853) heeft doen zien, dat van de niet schoolgande bevolking 4 pCt. en van de scholicren daarentegen $2 \frac{1}{2} \mathrm{pCt}$, in dat gesticht later is teruggekomen. Die nitkonst is verkregen onder een' zamenloop van ongunstige omstandigheden. Wat zoule zij niet hebben kunnen zijn onder gunstige omstandigheden!

Zoo nu goed schoolonderwijs in de gevangenissen het groote kankerkwaad van de zamenleving, de recidivisten, kan doen afnemen, dan voorzeker, mag dat onderwijs wel op hoogen prijs worden gesteld; dan mag gewis in hen die dat onderwijs geven, wel zooveel belangstelling getoond worden als $z i j$ verdienen, die den Staat eene onschatbare dienst bewijzen. Dit zal dan ook ongetwijfeld wel het geval zijn in Nederiand. het land waar de liefde en zorg voor het onderwijs zoo diep geworteld zijn, en dat daarin zoolang reeds den vreemde tot voorbeeld was?

De volgende vergelijkende tabel, naar aanleiding van een herhaald bezoek der Belgische verbetering- en strafgestichten, moge doen zien in hoeverre Nederland in dit opzigt met den nobuur kan wedijveren. 


\section{DE GEVANGENIS-SCHOOLONDERWIJZER IN BELGIE EN NEDERLAND, $A^{\circ}$. 1856.}

\begin{tabular}{|c|c|c|c|}
\hline $\begin{array}{c}\text { PUNTEN } \\
\text { YAN } \\
\text { VERGELIJKING. }\end{array}$ & BELGIF. & NEDERLAND. & TOELICHTINGEN. \\
\hline Onterwijzer. & $\begin{array}{c}\text { Bepaaldelijk voor } \\
\text { de gevangenis: }\end{array}$ & $\begin{array}{c}\text { In den regel tevens } \\
\text { plaatselijk onder- } \\
\text { wijzer. (a.) }\end{array}$ & $\begin{array}{l}\text { (a.) Alzoo de gevangenis- } \\
\text { dienst meer ene bij- } \\
\text { betrekking. }\end{array}$ \\
\hline Bezoldiging. & $\begin{array}{l}1600 \mathrm{Hr}=f 756(b .) \\
\text { (K. Besl., dd. } 27 \\
\text { Junij 1846. Mo- } \\
\text { mitew, No. 186.) }\end{array}$ & $\begin{array}{l}f 350 . \text { (c.) } \\
\text { (K. Besl., dd. } 11 \\
\text { Dec. 1822, No. } \\
\text { 116. De Jongh, } \\
\text { Terzamel., pag. } \\
\text { 155.) }\end{array}$ & $\begin{array}{l}\text { (b.) In de cathegorie der } \\
\text { voorgestelde tractements- } \\
\text { verhoogiug, ten gevolge } \\
\text { van de duurte der eerste } \\
\text { levensbehoeften. } \\
\text { (c.) } f \text { } 400 \text { voor de gevauge. } \\
\text { nissen der lste klasse } \\
\text { (bevolking boren de } \\
\text { 1000), welke echter } \\
\text { nog niet bestaan leb) } \\
\text { ben. Een enkele geniet } \\
\text { bij gunstige uitzondering } \\
f 150 \text { voor woning. }\end{array}$ \\
\hline Ambtsgrand & $\begin{array}{c}\text { Eerste commies (d.) } \\
\text { (K. Besl. als boven. } \\
\text { "Instituteurs et } \\
\text { lers Commis.") }\end{array}$ & $\begin{array}{l}\text { Tweede commies. } \\
\text { (Ministerieele dis- } \\
\text { positie, dd. } 15 \\
\text { Nor } 1856,4 \text { de } \\
\text { afd., No. } 75 . \text {.) }\end{array}$ & $\begin{array}{l}\text { (d.) Nist verpligt tot eenige } \\
\text { dienstkleeding. }\end{array}$ \\
\hline Werkzanmhederi. & $\begin{array}{l}\text { 1. Onderwijzen, } 1 \frac{1}{2} \\
\text { nur daags. } \\
\text { 2. Opmaken der al- } \\
\text { gemeene statis- } \\
\text { tiek. } \\
\text { 3. Bestuur en dienst } \\
\text { der bibliothcek. }\end{array}$ & $\begin{array}{l}\text { Onderwijzen, ge- } \\
\text { middeld 2 uren } \\
\text { daags, (les geven.) } \\
\text { (e.) }\end{array}$ & $\begin{array}{l}\text { (e.) Te Woerden houdt de } \\
\text { onderwijzer op zijn ver- } \\
\text { zoek sinds juren de bi- } \\
\text { bliotlleek. }\end{array}$ \\
\hline Sehooladministratie & $\begin{array}{l}\text { Gedrukte registers } \\
\text { volgens algemen } \\
\text { voorschrilt, zoo } \\
\text { voor de school } \\
\text { als statistiek. }\end{array}$ & $\begin{array}{l}\text { Geenerlei algemee- } \\
\text { ne reglementaire } \\
\text { voorschriften. }(f .)\end{array}$ & $\begin{array}{l}\text { (f.) Te Woerden zijn doer } \\
\text { den onderwijzer sedert } \\
\text { jaren versclillende re- } \\
\text { gisters aangelegd. (Met } \\
\text { de pen getrokken.) }\end{array}$ \\
\hline $\begin{array}{l}\text { litzigt op bevor- } \\
\text { dering. }\end{array}$ & Directeur. (g.) & Nihil. (h.) & $\begin{array}{l}\text { (g.) Een der onderwijzers } \\
\text { is tevens cantonnual } \\
\text { school-inspecteur. } \\
\text { (h.) Een enkele, geen plaat- } \\
\text { selijk onderwijzer, werd } \\
\text { bij uitzondering, vóór } \\
\text { vele jaren reeds, tevens } \\
\text { belast met de waar- } \\
\text { neming der functie } \\
\text { van tweeden commies } \\
\text { bij de directie over den } \\
\text { urbeid, tegen gedeelte- } \\
\text { lijk genot ran de jaar- } \\
\text { wedde dier betrekking. }\end{array}$ \\
\hline
\end{tabular}


Deze tabel kan, helaas, de schaal niet ten voordeele van Nederland doen overslaan. Waaraan is die ongunstige stand van verordeningen omtrent het schoolonderwijs in de gevangenissen alhier toe te schrijven? De ontwikkelde beantwoording hiervan zonde eene geheele geschiedenis zijn, te veel voor eene schets. Genoeg zij het hier, eerst en voornamelijk te herinneren aan den zorgelijken toestand van 's lands finantiën gedurende zoovele jaren. Maar die is nu geweken? Ja; maar intusschen heeft zich het gevoelen gevestigd: "let schoolonderwijs voor hejartde gevangenen is eene verlorene zaak." En alzoo bleef het onderwijs in de gevangenissen op den voet als toen het ten jare 1822 werd in 't leven geroepen. Men heeft, ongelukkig genoeg, alleenlijk gelet op het aantal recidivisten (over een tijdvak van 10 jaren gemiddeld $29^{5} \mathrm{pCt}$.), en daardoor het nog grooter aantal niet-recidivisten $\left(70^{5} \mathrm{pCt}\right.$.) buiten beschouwing gelaten. Enkel het antal recidivisten bij de bejaarden ziende, was de zorg en belangstelling bijzonderlijk gewijd aan de jeugdigen; hoezeer de recidivisten bij de veroordeelde jongens niet minder beduidend blijken: in 1854 was dit $28^{1} \mathrm{pCt}$. Men heeft den staf gebroken over eene zaak, zonder ze genoegzaam te kemnen, en daardoor geene aandacht genoeg gewijd aan het voornaanste middel, dat den kanker der misdaad bij herhaling zoo krachtig kan bestrijden. Dit geschiedde oindat zich nog geene gelegenheid had voorgedaan tot naanwkeurige in 't lichtstelling der uitkomsten van 't onderwijs in de gevangenissen voor bejaarden. En dit ware niet gebeurd zonder mangel aan bepaalde en algemeene verordeningen deswege.

In dezelfde groote gevangenis, boven bedoeld, heeft intusschen de onderwijzer zich reeds sedert negentien jaren, ondanks vele bezwaren, het bijhonden van uitvoerige en naauwkeurige aanteekeningen getroost, ten einde ééns in statistischen vorm de resultaten te kunnen geven van het schoolonderwijs voor bejaarden, in verband met den matschappelijken toestand, ouderdom en geaardheid van den veroordeelde. Die annteekeningen wachten thans op de gnnstige gelegenheid tot bearbeiding, tot verwerking. Moge nu met het einde van het twintigste notitiejaar dien onderwijzer de noodige opgewektheid en genoegzaam beschikbare tijd tot ongestoorde uitwerking van zijn statistisch ontwerp gegund zijn, dan zal kunnen aangetoond worden: $1^{\circ}$. wat het meest aannemelijk stelsel voor het schoolonderwijs in de gevangenis zij; $2^{\circ}$. de gang der wetenschappelijke ontwikkeling van den veroordeelde, in vergelijking met zijn' echtelijken staat, leeftijd en karakter. Dan zal men welligt tot het besluit komen, dat het toch niet wel was, niets ten behoeve van het onderwijs voor bejaarde gevangenen te doen, en den armen onderwijzer in den kerker zoovele jaren vergeten als , an luim en toeval" over te laten. 
De zekere en ginstige gang van zulk eene gewigtige aangelegenheid, als het onderwerpelijke onderwijs, moet door doeltreffende en algemeene verordeningen verzekerd en bestendigd worden. Dit mag thans meer, dan ooit verwacht worden, nu het Nederlandsche gevangeniswezen blijkbaar in eene overgangsperiode verkeert.

Indien men van den arbeid der schoolonderwijzers in den kerker gewenschte en bestendige vrnchten verlangt, van toeval en omstandigheid onafhankelijk, dan behoort ook die betrekking op den voet als in Belgie gereleveerd en verbeterd te worden. Hij, die nu zijnen invloed en zijne magt daartoe aanwendt, en dat tot stand weet te brengen, zal aan dezen tak van bet onderwijs, en aan Nederiand in 't algemeen, eene groote weldaad bewijzen, en zichzelven een gezegend aandenken verzekeren.

Moge bij eene vergelijking tusschen Belgie en Nederland over 1857 reeds de balans meer in den evenanr staan!

$$
\text { W. , } 4 \text { Februarij } 1857 . \quad \text { J. vaN DAM, Thz. }
$$

Op verzoek vall den inzender, plaatsen wij het navolgende:

is Hage, Mei. - Wij ontvingen dezer dagen prospectus en proefblad valı een nieuw tijdschrift op staathuishoudkundig gebied: Le nouvel Economiste, journal des principes et des faits économiques, waarvan de hoofd-redakteur Pascal Duprat, hoewel van opgewondenheid niet vrij te pleiten, zich op het vrij-handelscongres te Brussel door sierlijkheid en bondigheid van taal de algemeene toejuiching heeft weten te verwerven. Het tijdschrift verschijnt twee keeren 's maands, in twee, soms drie of vier bladen, te Lausanne, tegen den jaarlijkschen prijs van acht franken voor Zwitserland en tien voor het buitenland. Het stelt. zich de behandeling voor van de twaalf volgende hoofdpunten: de leer der staathuishoudkunde geput uit de geschriften, hare geschiedenis, de hervormingsplanneu en ontwerpen, de vorderingen op het gebied der nijverheid en van den landbouw, de crediet-instellingen, de spoorwegen, de vrij-handelsbeweging, de belastingen en geldleeningen, de statistiek, een overzigt der staathuishoudkundige periodieke en andere geschriften, eene levensbeschrijving der voormaamste staatshuishoudkundigen. In het eerste nummer worden met betrekking tot ons vaderland zeer geprezen onze handelshervormingen, vooral die op de visscherij, eene melding gemaakt van de artikelen in dit tijdschrift over de goudproduktie in Australië en Californië en haren invlood op de muntkwestie, en over den Europeeschen handel in Japan. Voorts worden onder meerdere geschriften, kort beoordeeld de Beginselen van staatshuishoudkunde, door den Redacteur van dit Tijdschrift, Amsterdam 1851 , J. H. Gebhard.

M. M. von BaumhaUer. 


\section{Correspondentic.}

Lan dem Redactarar van de Economist.

Op p. 100 van het nommer vau Huart van nw Tijdschrift vind ik de vraag geop* perd: "Wat is do oorzaak dat de tabakshandel in vergelijking van avdere zeeplaatsen albier over $t$ algemeen in verval is gerakt?" Eene van die oorzaken die ik niet ver. meld vind. is mij (het kan geweest zijn in 1827 of 1828) meêgedeeld door cen van de grootste handelaren in tabak te Amsterdam, den heer M. d. L. Deze zoide mij dat hịj. wegeus het anmienhik versehl in het bedrag der onkosten en ongelden, de ladingen tabak die hij kreeg, regtstreeks naar Hamburg zond; dat ook reeds anderen zijn voor" beeld volgden en de markt in het artikel alzoo dreigde te verloopen. Hetzelfde was 't geval met den handel in huileu die on dezelfde redeu zich naar Antwerpen verplaatste. Of lanrin sedert eene verandering ten goede gekomen is, weet ik niet, dooh het zou altoos geloof ik. niet onbelangrijk zijn, eane rergelijkendc tabol te levereu van de onkosten en ougehlen op cene lading vallende, bijv. te Hambarg, Bromen, Amsterdam, Rotterdam en Antwerpen.
APnTL.
Viw belaugstellende lezer,
W. F. S.

Een gedeeltelijke beantwoording zijner vaag viudt Corr. in de onderstannde opgave afgeschreven uit een Request, door de Kamer val kooph. en Frobr. te Amsterdar, in 1854 ingediend, en afschaffing van het tonnengeld der zeeschepen rerzoekende

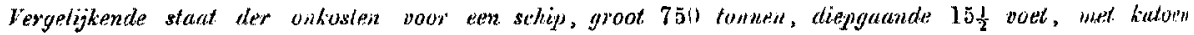
binnenkomende, en beladen weder witgande net eeten diepgnay van 18 voet, in de navolgende haveas.

\begin{tabular}{|c|c|c|c|c|c|c|c|}
\hline \multirow{3}{*}{$\begin{array}{l}\text { BENAMIAG DER ONE. } \\
\text { Loodsgeld. }\end{array}$} & ANTWERPSN & LONDEN. & Lrvenpoor. & Breartint. & HАMBURG. & \multicolumn{2}{|c|}{ Aओ:TFRJAH } \\
\hline & Bimnent. Uitu. & Bimnenk. Vigs. & Bimenk. Titg. & Bin. Uitg. & Binuenk. Uitg. & Bimatenk. & Uitgo, \\
\hline & $f \mid i 4,34 f 238.93$ & $f 180-f 143,60$ & $f 79.0 \mathrm{a} f \quad 43.30$ & $f 70$ & MBo. $350 .-$ & $f(32$ & $f^{\prime} 100$ \\
\hline Tounengeld. & " $387,38 \times 387.38$ & "28.50" 29.50 & $\ldots$ & $\ldots \ldots$ & $\ldots$ & 1781.37 & " $3 \mathrm{~N} 1.3 \pi_{4}$ \\
\hline Vuur, ton $s$ ligkengeld & $" 32.96 " 32.95$ & $" 172.90 " 140.40$ & $+180 .-" 180 .-$ & $\ldots$ & 150 & " 120 & $" 47.25$ \\
\hline Haven-en dokgeld, & $\# 248.03 \quad \ldots$ & $735.60)+355.50$ & $.309 .37+300.29$ & $\Rightarrow 49 . * 48$ & 船- & $" 80.73$ & $\ldots$ \\
\hline Onkosten te Y. Diep. & $\ldots$ & $\ldots \ldots$ & $\ldots \ldots$ & $\ldots$ & $\ldots$ & $\Rightarrow 80 .-$ & $" 20 .-$ \\
\hline Stader-tolonkosten. & $\ldots$ & $\ldots$ & & $\ldots$ & 300.- & $\cdots$ & $\ldots$ \\
\hline Mectbrief. & y 26.37 & ... & & . & $\cdots$ & 24.15 & $\ldots$ \\
\hline Ankargela. & $\ldots$ & $\ldots$ & $"-.01$ & $\cdots \quad$, & & $\cdots$ & $\ldots$ \\
\hline Stantsbelastingr. & $\ldots$ & $\ldots$ & ... & 432.732 & & 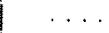 & $\ldots$ \\
\hline Stoomb. uit nam ree. & & T. M. & P. M. & $\ldots$ & & P. M. & P. $\mathbf{~} 1$ \\
\hline Siuisg. N. H. kanaal. & $\ldots$ & ... & $\ldots$ & . . . & & $" 150 .-$ & $" 9111_{2}$ \\
\hline Loots op h. N. H. Kath. & $\ldots$ & $\ldots$ & & & & $n \quad 37,30$ & \# 34.90 \\
\hline Paarüen 18 ì $f 10.50$ & $\ldots$ & & & . & & $\# 100$. & $n 190$ \\
\hline Sleepboot over het $1 \mathrm{~J}$. & $\ldots, \ldots$ & $\ldots$ & $\ldots$ & ... & & " 46. - & n 46.- \\
\hline Kleine ongelden. & $" 90.95 " 35.31$ & "3.- & 13.60 & $\cdots$ & $123,-$ & $" \quad 2 \check{5} . \cdots$ & " 25: \\
\hline Totalen. & $f 064.05 f 004.59$ & $f 139.80$ f 708. & $f 584.02 f 532.58$ & $f 150 . f 100$ & $\begin{array}{c}\text { MBo. } 700: 700 . \\
\text { is } f 490 \text {. }\end{array}$ & $f 1250.5$ & $f 039.321$ \\
\hline
\end{tabular}

Op dezen staat komt Austerdam voorzeker in een ongunstige verhouding: voor in- en uitklaring $f 2189$ tegen $f 310$ te Bremerhayen. Men onthoude echter dat thans een goed gedeelte dezer onkosten, 
sedert de afschaffing van het tomengeld. net 1856 is komen te vervallen, gelijk 0 . a, werd aaugetoond in een vergelijkend staatje der oukosten te Amsterdau voor een schip van 330 ton in 1849 en 1856 , (Economist 1 Januarij 1l. p. 23), waarvoor de scheepsongelden in het eerstgemelde jaar $f$ 1673, in het tweede $f 1052$ bedroegen. Bij een ontwerp tot vermindering van het tunnengeld der zeeschepen, in 1852 door den toenaligen minister van funancion, den heer v. Bosse ingediend, vindt men in een der gewisselde stukken ook eene vergelijkende opgave van de onkosten die in rerschillende havens gedragen worden. Daarbij wordt echter gewezen op het moeijclijke om volkomen juiste opgaven van al de gezamenlijke onkosten te bekomen, daar de kleine, die bijeengeroegd somtijds een niet onaanzienlijk bedrag uitmaken, vaak global of in duistere posten worden opgegeven. Echter wordt, wat eenige groote onkosten betreft, het navolgende resultaat. opgemankt: voor een schip van 500 tomnen, komende van Z.-Amerika: Ainsterdain / 1446.-, Antwerpen / 975.-, Bremen / 426.-, Hamburg $\int 560 .-$. De loodsgelden bedragen in die opgaven voor elk der havens vau $/ 200$ à $f 280$; de hoogere onkosten voor Amsterdam worden veroorzaakt door het tommegeld $f$ 50S. - en de onkosten op het N.Hollandsche Kanal, met jaagloon $f 446 .-$, te zamen dus

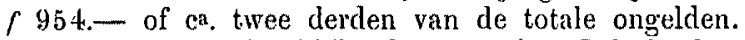

Uit een en ander blijkt dus wel dat Nederland, en vooral Amsterclam, uit het oogpunt der baven-onkosten, in eene nadeelige positic verkeerde; doch dit moge al als bijzaak hebben medegewerkt, de hoofd-oorzaak zal het wel niet geweest zijn. - De groote zaak voor Nederland, ten aanzien van vaart eu handel op Noord-Amerika, is lat wij geene vitvrachten, geene noemenswaardige altans, derwarts hebben, noch wat goedereu, noch wat emigranten betreft. En toch mijn wij voor beide, als exporteurs roor Duitschland, zoo nitnemend gelcgell. Het aandeel in het transport der landverhuizers is voor Nederland, (de natumlijke uitweg voor Duitschland), in vergelijking van andere havens volkomeu onbeduilend: elk der statistieke overzigten van landverhuizing wijst dit aan. En toch, Bremen en Havre hebben getoond, hoe het ter harte nemen en bevorderen der Noord-Amerikaansche emigrantentransporten, op den goederenhandel, door anvoer van Amerikaansche uitvoer-artikelen, voordeelig terugwerkt. Aan die uitvrachten van landverhnizers, door het juerig aankmoopen van directe relatiën geholpen. heeft BREMEN gedeeltelijk zijn tabakshandel. heeft HaVRE grootendeels zijne katoenmarkt te clanken.

De laatste jaren (dank voorzeker, onder meer, aan de scheepvaart. wetten van 1850), schijnen echter, ook wat den overzeschen handel hetreft, in velerlei opzigten verbetering an te bieden, en aanzienlijk is de toeneming van onzen handel, ook naar plaatsen die vroeger ninmer bezocht werden. 